\title{
ENHANCING STUDENTS' MOTIVATION: THE EFFECT OF A STRUCTURED ORAL EXAMINATION IN BASIC CLINICAL SKILLS TRAINING
}

\author{
Ratih Yulistika Utami ${ }^{1 *}$, Oppi Mirzatillah², Desi Isnayanti ${ }^{3}$, M. Jalaluddin Assuyuthi Chalil ${ }^{4}$ \\ ${ }^{1}$ Medical Education Unit, Faculty of Medicine, Universitas Muhammadiyah Sumatera Utara, Medan - INDONESIA \\ ${ }^{2}$ Faculty of Medicine, Universitas Muhammadiyah Sumatera Utara, Medan - INDONESIA \\ ${ }^{3}$ Secretary of Undergraduate program, Faculty of Medicine, Universitas Muhammadiyah Sumatera Utara, Medan - INDONESIA \\ ${ }^{4}$ Department of Anesthesiology, Faculty of Medicine, Universitas Muhammadiyah Sumatera Utara, Medan - INDONESIA
}

Submitted: 18 Apr 2020; Final Revision from Author: 19 Oct 2020; Accepted: 29 Dec 2020

\begin{abstract}
Background: Basic Clinical Skills (BCS) is one of the learning methods in medical education that acts as an intermediary bridge to apply procedural knowledge and clinical competency for medical students. Medical educators have successfully used many ways to assess students' abilities, both oral and written. Oral examinations have vast advantages compared to other assessment methods. However, no standardization of questions to be tested becomes an essential issue in the assessment process. A structured oral examination may increase students' motivation to prepare themselves better to study the material before following BCS training. This study aimed to determine the effect of a structured oral examination on students' motivation and identify students' motivation.

Methods: This quasi-experimental research used a pretest-posttest design to assess the effect of applying the structured oral examination on students' motivation. The subject of this study was the third-year medical students that amounted to 109 students. Sample selection was made by total sampling. In this study, the authors used SMQ-II questionnaires to measure the students' motivation.

Results: This research showed significant differences between student motivation on pretest and posttest (p-value of 0,000) after the students were given the structured oral examination at the beginning of basic clinical skills training. It means the structured oral examination affected students' motivation.

Conclusion: The structured oral examination administered for students before entering BCS learning processes had a significant impact on the students' motivation. The preparation and the regulation of the structured oral examination on the BCS learning processes should be reinforced to motivate the students and make them more skillful.
\end{abstract}

Keywords: clinical skills, structured oral assessment, motivation, skill training, undergraduate program

*corresponding author, contact: dr.ratih.utami@gmail.com 


\section{PRACTICE POINTS}

- A structured oral assessment in basic clinical training for undergraduate students can be applied because it encourages students' motivation.

- This assessment also reflects students' preparation before keeping up with the training and improves their knowledge.

- This assessment's novel aspects were: 1) it comprised three different levels of difficulty, namely: difficult, moderate, and easy; 2) students were asked from difficult to an easy question, respectively. They were not asked the easy question if they answer the difficult question correctly.

\section{INTRODUCTION}

As one of the learning methods in health (mostly medicine), Basic Clinical Skill (BCS) has proven to have many benefits for medical students ${ }^{1}$ since it acts as an intermediary bridge for applying procedural knowledge and clinical competence. ${ }^{2}$ It can be performed by role play, the use of a mannequin as a teaching aid to support the learning process, and simulated/standardized patients for specific purposes. ${ }^{3}$ Clinical skills in the undergraduate program are assessed with Objective Structured Clinical Examination (OSCE), even though oral examinations are also a standard method to evaluate students' knowledge and professionalism in the clinical rotation..

Medical educators have successfully used many methods to evaluate students' abilities, including oral and written assessments. ${ }^{4}$ An oral method is defined as a method that allows students to provide a verbal response to any tasks expressed through words rather than written. ${ }^{5}$ This method has also been used to assess whether the students use scientific languages correctly and adequately according to the content, looking calm when given questions, and posing a professional and ethical attitude when interacting. ${ }^{6}$ However, it also has deficiencies in the application, such as lack of standardization in terms of questions to be tested, limited coverage of the material, the possibility of causing anxiety to students, lack of testing records, and absence of rewards or punishment whether the students can response the questions correctly or not. ${ }^{7}$ Thus, those reasons can be feared to be the causes of the lack or the absence of students' motivation in facing oral examinations. ${ }^{\text {? }}$

Oralexaminationsareconducted beforestudentsenter the clinical skills laboratory, and the examinations become one of the requirements to follow the BCS process in FM-UMSU. Based on the initial interviews with some fourth-year students, there are some obstacles in implementing oral examinations, such as lack of standardization or subjectivity in the examination rating. Shenwai \& Patil stated that traditional oral examinations were easy to conduct, and they offered flexibility for the examiner to assess/ evaluate the students' comprehensive knowledge about a subject. This method may not be fair because of some shortcomings in the uniformity of questions and their difficulty level. ${ }^{8}$ Secondly, it reduced the time of the teaching and learning process in the BCS when the instructors were late; therefore, this might decrease students' motivation to prepare for the oral examinations. The students would gain an in-depth understanding if they had an opportunity to design and understand the learning process. ${ }^{9}$

This study aimed to determine the effect of oral examinations in the BCS process on students' motivation and determine the description of their motivation

\section{METHODS}

This quasi-experimental research used a pretestposttest design to assess applying oral examinations in the BCS process on the students' motivation. The 
subjects were medical students in their third year. There were 109 students still actively participating in BCS learning activities, and they were all selected as the samples using a total sampling technique or broad sampling. Prior to sample selection, this research had obtained permission from the research ethics committee of medical and health research, FM-UMSU, on September 12, 2017, Number: 03/ KEPK/FKUMSU/2017.

In this study, the authors used the Science Motivation Questionnaire (SMQ) II to measure the students' motivation. SMQ II consists of 25 questions within five components, in which each component has five questions. This questionnaire comprises a Likert scale of 1-5 (1: never, 2: rare, 3: sometimes, 4: often, 5: always). Before starting the validity test, the questionnaire was first translated and back-translated by two different English language graduates. Second, both the English language graduates were asked to fill in the table of conformity of the questionnaire content, whether the questionnaire had the same range (intent and purpose) of each question. Third, the legibility test was conducted to assess whether the reader could understand each item in the questionnaire by two students outside the research subjects. Fourth, validity and reliability tests were conducted by giving questionnaires to 30 students. At least 30 samples were required for the experimental study to obtain the measurement results' value distribution close to normal. ${ }^{10,11}$

Validity tests and reliability tests are two different tests with different meanings. A validity test is a test of accuracy or precision of the instrument used to measure what will be measured (in this case, the motivation). In contrast, the reliability test is a reliability test of the research instrument. Reliable means that the measuring instrument can be used anytime and anywhere. ${ }^{12}$ Although validity and reliability tests have different meanings; this test has the same goal to determine if the measuring tool used can produce valid data to answer the research problem. ${ }^{11,12}$
Tabel 1. Validity test of SMQ-II questionnaire

\begin{tabular}{|c|c|c|}
\hline Questions & $\begin{array}{l}\text { Pearson's } \\
\text { correlation }\end{array}$ & Conclusion \\
\hline 1 & 0,034 & Not valid \\
\hline 2 & 0.596 & Valid \\
\hline 3 & 0,425 & Valid \\
\hline 4 & 0,075 & Not valid \\
\hline 5 & 0,679 & Valid \\
\hline 6 & 0,257 & Not valid \\
\hline 7 & 0,777 & Valid \\
\hline 8 & 0,808 & Valid \\
\hline 9 & 0,759 & Valid \\
\hline 10 & 0,676 & Valid \\
\hline 11 & 0,200 & Not valid \\
\hline 12 & 0,705 & Valid \\
\hline 13 & 0,746 & Valid \\
\hline 14 & 0,731 & Valid \\
\hline 15 & 0,754 & Valid \\
\hline 16 & 0,651 & Valid \\
\hline 17 & 0,727 & Valid \\
\hline 18 & 0,711 & Valid \\
\hline 19 & 0,489 & Valid \\
\hline 20 & 0,677 & Valid \\
\hline 21 & 0,731 & Valid \\
\hline 22 & 0,595 & Valid \\
\hline 23 & 0,645 & Valid \\
\hline 24 & 0,685 & Valid \\
\hline 25 & 0,686 & Valid \\
\hline
\end{tabular}

Table 2. Reliability test of SMQ-II questionnaire
Cronbach alpha

0,944
No of items

21
The validity test was done by comparing $r$-count with r-table. The value is valid if the $r$-count is greater than $\mathrm{r}$-table $(0.3) .^{10,13}$ The result of the validity test showed that there were 4 invalid questions, i.e., intrinsic motivation (question number 01, r-count 0,034), grade motivation (question number 04, 
r-count 0,075 ), self-determination (question number 6 , r-count 0,257 ), and self determination (question number 11, r-count 0,2). The authors used expert validity, who was a psychologist, to confirm the construct validity test. The expert justified that the invalid questions were not included in the questionnaire because of three considerations. First, the construct validity test showed that the questions were not valid, and they could not measure the component. Second, the reference of SMQ in this study did not come from the main reference, and the research was conducted in the different locations on a demographic basis so that there was a possibility that the item formulation of the reference had not been valid for the local context. Third, the five components were still represented by 3 to 5 items; the gap in the number of items represented that each component did not differ significantly.

Meanwhile, the reliability test was done by comparing the Cronbach alpha count's value with the minimum alpha value. The item will be reliable if the Cronbach alpha value is higher than the minimum Cronbach alpha (0.6). The result of the reliability test showed that the value of Cronbach alpha was 0,944. It meant that the questionnaire SMQ II with 21 questions was declared valid and reliable as an instrument to measure student motivation in this study. ${ }^{10,13}$

The authors and Head of the BCS Division compiled a list of questions and answers tested to the subjects. The terms and conditions for the questionnaire preparation were: (1) The items should be following the BCS material that would be studied by the respondent. (2) Each item's difficulty level should be different (starting from the hardest, middle, to most manageable level). The questions were prepared by considering the 'must know,' 'desirable to know,' and 'nice to know' aspects. These questions comprised the recall, the analytical, and the reasoning types. The items were arranged in ascending order according to their difficulty level.

The authors explained the objectives, the research implementation procedures (implementation time and mechanism), the BCS learning process rules, and the informed consent. The research implementation method included: (1) each instructor was given a list of questions and answers that must be tested on this study's subject. (2) oral examinations were held in turn so that all students had to wait for their turn outside the room and went in one by one. The oral examination had a maximum duration of 15 minutes, with five to six students in one class. All of the subjects were divided into twenty groups/ classes and were tested by twenty instructors. (3) Each student was given three questions of different difficulty levels: difficult, moderate, easy. (4) Students who could answer the first question (difficult) correctly were welcome to settle in the room directly and waited for the BCS learning process to begin (not required to answer the second question). Students who could not answer the first question correctly then got a second chance to answer the second question with a moderate difficulty level. If the student could correctly answer the second question, they could follow the BCS learning process. Nevertheless, if the student could not answer the second question correctly, the student was given the last question with a manageable difficulty level. If the student successfully answered the third question adequately, the student could follow the learning process. Thus, the student could not attend the BCS lesson at the meeting as they would be subject to the remedial process.

The authors collected the pretest data and implemented the structured oral examinations for two blocks (Special sense and Dermatomusculoskletal). Each block had 5 BCS learning processes, and complete ten sets of questions were used in this study. The authors explained that the research had been completed to request the subject approval to fill the posttest data. 
Table 3. Examples of the questions for the structured oral examination on Dermatomusculoskeletal system

\begin{tabular}{|c|c|c|c|}
\hline No & $\begin{array}{l}\text { Level of } \\
\text { difficulty }\end{array}$ & Questions & Answers \\
\hline 1. & Difficult & $\begin{array}{l}\text { A } 30 \text {-year-old-man was brought to an } \\
\text { emergency room by his family with a closed } \\
\text { fracture of the right lower leg, and the patient } \\
\text { is compos mentis. The patient got an accident } \\
\text { with a motor crush one hour before coming } \\
\text { to the hospital. What should students do to } \\
\text { this patient? }\end{array}$ & $\begin{array}{l}\text { Primary survey } \\
\text { Secondary survey } \\
\text { Put up a splint on the right lower leg (do the } \\
\text { reposition if needed) } \\
\text { Give an analgetic } \\
\text { Request radiology examination } \\
\text { Consult with an Orthopedics specialist }\end{array}$ \\
\hline 2. & Moderate & Explain the distal neurovascular examination? & $\begin{array}{l}\text { Neuro } \\
\text { Sensory: ask the patient to what kind of } \\
\text { sensation felt when the student touches his } \\
\text { fingertips } \\
\text { Motoric: ask the patient to move the } \\
\text { fingertips } \\
\text { Vascular } \\
\text { Palpate the arteries } \\
\text { Palpate the fingertips }\end{array}$ \\
\hline 3. & Easy & $\begin{array}{l}\text { What is the aim of applying a bandage or a } \\
\text { splint? }\end{array}$ & $\begin{array}{l}\text { To immobilize the fractured part of the body } \\
\text { so that can reduce the pain and }\end{array}$ \\
\hline
\end{tabular}

\section{RESULTS AND DISCUSSION}

This study's total samples were 109 students: 41 were men $(37.6 \%)$, and 68 were women $(62.4 \%)$. The mean of students' motivation before and after the intervention was assessed by adding the motivation score divided by the number of samples.

Table 4. The mean of pretest and posttest motivation

\begin{tabular}{lccccc}
\multicolumn{1}{c}{ Motivation } & $\mathrm{N}$ & Min & Max & Mean & Std. Deviation \\
Pretest & 109 & 2.714 & 5.000 & 3.68152 & .410336 \\
Posttest & 109 & 3.000 & 5.000 & 4.28528 & .473293 \\
\hline
\end{tabular}

The minimum and the maximum pretest motivation posttest motivation scores were 3 and 5 respectively, scores were 2.714 and 5 respectively, with the mean with the standard of 4.28528 . of 3.68152, while the minimum and the maximum

Table 5. The mean of per-item motivation

\begin{tabular}{lccccc}
\multirow{2}{*}{ Group } & \multicolumn{5}{c}{ Mean of motivation items } \\
\cline { 2 - 6 } & $\begin{array}{c}\text { Intrinsic } \\
\text { Motivation }\end{array}$ & $\begin{array}{c}\text { Career } \\
\text { Motivation }\end{array}$ & $\begin{array}{c}\text { Self- } \\
\text { Determination }\end{array}$ & $\begin{array}{c}\text { Self- } \\
\text { Efficacy }\end{array}$ & $\begin{array}{c}\text { Grade } \\
\text { Motivation }\end{array}$ \\
\multirow{2}{*}{ Pretest } & 3.595 & 3.844 & 3.537 & 3.726 & 3.618 \\
Posttest & 4.2325 & 4.482 & 4.093 & 4.31 & 4.203 \\
\hline
\end{tabular}


The highest mean of motivational items was Career Motivation in both the pretest and the posttest, while the lowest mean was Self-Determination. The highest posttest-pretest mean difference was 0.638 , while the lowest was 0.556 .
Meanwhile, the pretest and the posttest p-values of the normality test were 0.451 and 0.56 , respectively. Since both data got a p-value of more than 0.05 , the pretest and posttest motivation data were normally distributed. Therefore, the test was continued by using a paired t-test.

Table 6. Paired t-test: the significance test of pretest and posttest motivation difference

\begin{tabular}{lcccc}
\multicolumn{1}{c}{ Motivation } & Mean & Diff & CI 95\% & p-value \\
Pretest & 3.68152 & & & \\
Posttest & 4.28528 & 0.60376 & $0.506736-0.700779$ & 0.000 \\
\hline
\end{tabular}

The paired t-test (Table 4.3) resulted in a p-value of 0.000 or $<0.05$; thus, there was a significant difference between pretest and posttest motivation. This meant that the structured oral examination affected student learning motivation. This study's effect size was 1,18 , which indicated that the structured oral examination strongly affected the students' motivation in basic clinical skill training.

Findings revealed a difference between student learning motivation on the pretest and the posttest after they were given the structured oral examination before starting the BCS process. This meant that the structured oral examination affected student motivation with an effect size of 1.18. This was consistent with the different mean of the posttest and the pretest by 0.60376 . Rushton P, Balran, and Farnsworth confirmed that a structured oral examination gave better results or scores in learning and affected learning motivation. ${ }^{14,15}$ The structured oral examination was an equitable, reliable, valid, and uniform tool for assessing students' capacity. $16,17,18,19$ Students feel very comfortable and relaxed with the structured oral examination regarding the uniformity of the questions asked, stress, time allotment, and topic coverage. The faculty find it a useful tool to ensure uniform coverage of mustknow areas for reducing bias. ${ }^{16,17}$ Also, the structured oral examination improved students' performance and skills in communication and critical thinking through a different means of engaging with the material. $18,20,21$
Williams and Hak's article suggested that there were some positive and negative aspects of the oral examination..$^{22}$ The positive aspects include students who feel benefited by the oral examination that is not too time-consuming compared to the written tests and students who think the fairness between one student and another because of uniformity. However, the oral examination has some negative aspects in that it can provoke anxiety before facing oral exams (conditioned stress). In addition, the examination also provides limited or less varied types of questions to be tested. ${ }^{15,22}$ In contrast, Shenwai and Patil suggested that structured oral exams could reduce bias and luck factor; and anxiety or fear amongst the students. 8 In this study, the students' anxiety may have been due to fear of not answering the questions correctly and adequately, so they will not be allowed to follow the BCS process at that time. The students' concerns in this study have not come from the oral examination itself.

On the other hand, Pope WDB's research showed that structured oral methods have some disadvantages. One of these disadvantages is the absence of reward or punishment if the student cannot answer the questions correctly and adequately. Therefore, this can reduce students' motivation to prepare them to deal with oral examinations. ${ }^{7}$ Students will be motivated if they know the objective and the kind of assessment, which is a formative or summative assessment. In this study, the punishment if students could not answer the questions correctly and 
adequately was that they could not join the learning process. The authors confirmed this punishment from the students' interviews, even though the authors did not ensure it by the instructor's interview or the video recording for a triangulation process.

Despite the mostly positive findings, heightened testing anxiety seems to be a key feature of oral examinations. ${ }^{23}$ Students were initially more anxious about oral examinations because they were unaware of the test format. Students were also reported to spend about the same amount of time studying for an oral examination than a written one. ${ }^{20}$ Students were more nervous in oral examinations, but they performed better compared to written ones. These suggest that anxiety could be attributed to many factors, including the expectations that verbal tasks require greater understanding or acting in a professional setting socially. ${ }^{24}$ Another finding revealed that a structured oral examination provides some advantages in terms of the comprehensive coverage of topics and reduced anxiety, improves the teacher-student relationship, and offers multiple choices, objectivity, uniformity, and the opportunity to answer without threat fear of the examiners. ${ }^{25,26}$ It has been established that fear and anxiety have an inverse relationship with the performance. ${ }^{27}$

Meanwhile, other factors influencing the implementation of a standardized or structured oral examination were rigid time limits, a lack of flexibility in knowledge content, monotony, and fatigue. The students perceived this format as the same as the conventional oral examination. However, they felt that it required an in-depth preparation of the topic. ${ }^{28,3}$ This preparation process positively impacts engagement with theoretical knowledge, and such efforts encourage students to explore the theory that corresponds with an in-depth laboratory session. ${ }^{18}$

The faculty opined that a structured oral examination led to less drift from the main topic and provided a uniform coverage of issues in a given time. Conducting a structured oral examination is a resource-intensive exercise. Despite being a structured test, inter-examiner variability is not eliminated. The students' performance depended on examiners' factors such as teaching experience, the vernacular language used, and the lack of training. Orientation and training of examiners in assessment strategies are necessary. Standardization of the questionnaire is required before the implementation of a structured oral examination for a summative assessment. ${ }^{28}$ However, another study found that this examination pattern provides equitable questions, balanced time, a comfortable environment, vast choices for answering, a regular assessment, a precise measuring capability, and objectivity, and increases the students' faith in the assessment system. It improves students' verbal skills and diminishes such biases as teacher favoritism, subject topic asked, and the examiners' mood on the assessment day. The oral examination also balances theory and practice with EvidenceBased Assessment such as OSPE and OSCE. ${ }^{19}$

Structured oral examinations achieve reliabilities appropriate to high stakes examinations if suflcient resources are available. ${ }^{29}$ The structured oral examination in this study demonstrated psychometric properties suitable for a formative test with low cost, ease of administration, and acceptability. It may be a useful method to assess physician competencies in training programs. ${ }^{30}$

This assessment required students' engagement with content. It meant that students were motivated to make more effort to learn. ${ }^{18}$ In this study, the Career Motivation item was the highest mean score in both the pretest and the posttest, while the SelfDetermination item was the lowest. In the research conducted by Susan and Turan, Career Motivation positively affected the students' motivation outcomes. ${ }^{31,32}$ There were two factors influencing motivation, namely, intrinsic and extrinsic factors. Intrinsic factors reflected individual awareness of the importance of learning and its usefulness for selfdevelopment and life provision.

In contrast, extrinsic factors resulted from outside the individual in terms of stimuli from others or the environment that could psychologically affect the individual. These extrinsic factors included parents and family, friends, learning environment and shelter, and learning-related instrument factors such as curriculum (including assessments and learning methods), facilities and infrastructure, and educators' 
ability to educate. ${ }^{33}$ Career motivation is a part of extrinsic motivation. This study revealed that oral examination could enhance students' motivation (mainly their extrinsic motivation). A previous study suggested that an assessment program should be constructed to motivate students to learn. The value of a test and students' expectations are vital as motivational factors. ${ }^{34}$ Students' expectations relate to successfully taking an examination, impacting their skills and future career as a doctor. The expectancy of success can be defined as individuals' beliefs about how well they will do on upcoming tasks, either in the immediate or longer-term future. ${ }^{35}$ The structured oral examination in this study had a reward and a punishment in that failed students could not attend the BCS.

Furthermore, several demotivators are present in an examination, such as time conflict, unfair standardsetting, and too many resit possibilities. ${ }^{34}$ In this study, there were no other activities that coincided with the examination because it was a prerequisite to attending basic clinical skill training. In terms of standard-setting, as long as students could answer the question correctly, they could pass the examination and continued the learning process. Students got three opportunities to answer questions with different difficulties (difficult, moderate, and easy). If they could not answer the easy one, they should attend the BCS training later. This regulation might be a factor that enhances students' motivation. In line with the previous study, the absence of remedy possibilities and performances without consequences could be one demotivator, so those should be prevented. ${ }^{36}$

Finally, oral examinations' biases and subjectivity can be reduced by introducing a structured oral examination despite the limitations, including time constraints, faculty availability, and initiative to bring out such changes. A structured oral examination can increase the validity and reliability of an oral assessment. The monotony of asking the same questions to all students can be avoided by creating more sets of questions/checklists with an adjusted difficulty level. Those questions will maintain uniformity and objectivity besides imparting some flexibility to the examiner.

\section{CONCLUSION}

A structured oral examination for students before entering BCS learning processes are likely to affect the students' motivation. The examination enhances the students' learning motivation as they are satisfied with the clear objectives; it has a reward and punishment. The oral examination regulation prior to the BCS learning processes should be reinforced so that students are more motivated to prepare for the learning process and improve their skills.

\section{RECOMMENDATION}

It is crucial to let experts develop and validate the structured oral examination items regarding their structure and their level of difficulty before using them. Moreover, as well as Structured Oral Clinical Assessment (SOCA), further study is beneficial to explore applying a structured oral examination to assess clinical reasoning and critical thinking and how this assessment method affects those skills. Critical thinking and clinical reasoning are the basis for implementing procedural skills.

\section{COMPETING INTERESTS}

The authors declare that there are no competing interests related to this study.

\section{AUTHORS' CONTRIBUTION}

Ratih Yulistika Utami - give research ideas, conduct study, write and revise the manuscript.

Oppi Mirzatillah - conduct study, collect and analyze data, and write the manuscript.

Desi Isnayanti - develop items in the structured oral examination, and review the manuscript.

M. Jalaluddin Assuyuthi Chalil - review items in the structured oral exam and review the manuscript.

\section{REFERENCES}

1. Curry RH, Makoul G. An Active-learning Approach to Basic Clinical Skills. Academic Medicine. 1996 Jan 1; 71(1): 41-44.

2. Lehmann R, Bosse HM, Simon A, Nikendei C, Huwendiek S. An innovative blended learning approach using virtual patients as preparation 
for skills laboratory training: perceptions of students and tutors. BMC medical education. 2013 Feb 12; 13(1): 23.

3. Rush S, Ooms A, Marks-Maran D, Firth T. Students' perceptions of practice assessment in the skills laboratory: An evaluation study of OSCAs with immediate feedback. Nurse education in practice. 2014 Nov 30; 14(6): 627-34.

4. Epstein RM. Assessment in medical education. New England Journal of Medicine. 2007 Jan 25;356(4):387-96.

5. Joughin G. Dimensions of oral assessment. Assessment \& Evaluation in Higher Education. 1998 Dec 1; 23(4): 367-78.

6. Wass V, Wakeford R, Neighbour R, Van der Vleuten C. Achieving acceptable reliability in oral examinations: an analysis of the Royal College of General Practitioners membership examination's oral component. Medical education. 2003 Feb 1; 37(2): 126-31.

7. Pope WDB. Anesthesia Oral Examination (editorial). Canadian Journal of Anesthesia.2000; 40: 907-10.

8. Shenwai MR, Patil KB. Introduction of structured oral examination as a novel assessment tool to first-year medical students in Physiology. Journal of Clinical and Diagnostic Research. 2013; 7(11): 2544-47.

9. Pogacnik, Cigic. How to motivate students to study before they enter the Lab. Journal of Chemical Education. 2006; 20(20): 1-5.

10. Dahlan S. Seri Statistik Statistika untuk Kedokteran dan Kesehatan Uji Hipotesis dengan Menggunakan. Jakarta: PT Arkans. 2004: 48-111

11. Hamdi AS, Bahruddin E. Metode penelitian kuantitatif aplikasi dalam pendidikan. Yogyakarta: Deepublish; 2014.

12. Sastroasmoro S, Ismael S. Dasar-Dasar Metodologi Penelitian Klinis. 5th ed. Jakarta: Sagung Seto; 2014.

13. Notoatmodjo S. Metodologi penelitian kesehatan Jakarta: Rineka cipta; 2010.
14. Rushton P, Eggett D. Comparison of written and oral examinations in a baccalaureate medicalsurgical nursing course. Journal of Professional Nursing. 2003; 19(3): 142-8.

15. Balran A, Farnsworth B. Oral exams: an alternative evaluation method. Nurse Educator. 2004; 22 (4): 6-7. 2004

16. Ponnudhali D, Bhandary S, Jones E. Structured Oral Examination - A Valid And Reliable Assessment Tool For First Year MBBS Students. National Journal of Basic Medical Sciences. 2016; 7(2): 99-105.

17. Vankudre AJ, Almale BD, Patil MS, Patil AM. Structured Oral Examination as an Assessment Tool for Third Year Indian MBBS Undergraduates.

18. Wang F, Khalaf AT, Lei D, Gale M, Li J, et al. Structured oral examination as an effective assessment tool in lab-based physiology learning sessions. Adv Physiol Educ. 2020; 44: 453-458. DOI: $10.1152 /$ advan.00059.2020

19. Imran M, Doshi C, Kharadi C. Structured and unstructured viva voce assessment: A double-blind, randomized, comparative evaluation of medical students. Int J Health Sci. 2019; 13(2): 3-9.

20. Dredge K, Sara G, Sheena G, Kathleen C, Bennallack, Taciana P, Dylan H, O'Brien, Jace H. Providing an Oral Examination as an Authentic Assessment in a Large Section, Undergraduate Diversity Class. IJ-SoTL. 2019; 13(2): 1-14. https://doi.org/10.20429/ijsotl.2019.130210

21. Crist JF, Robinson K. Stewards of the word: Employing oral examinations in required theology courses. Journal of Catholic Higher Education. 2015; 34(2): 235-256.

22. Williams and Hak. Study at a School of Pharmacy in North Carolina, Lindley, Mackowiak. 2004

23. Sparfeldt, JR, Rost DH, Baumeister UM, Christ O. Test anxiety in written and oral examinations. Learning and Individual Differences. 2013; 24: 198-203.

24. Huxham M, Campbell F, Westwood J. Oral versus written assessments: A test of student 
performance and attitudes. Assessment \& Evaluation in Higher Education. 2012; 37(1): 125-136.

25. Torke S, Abraham RR, ramnarayan K, Asha $\mathrm{K}$. The impact of viva-voce examination on students' performance in theory component of the final summative examination in physiology. J Physiol Pathophysiol. 2010; 1: 10-2.

26. Verma A, Mahajan N, Patel J. Evaluation and comparison of results: Conventional viva vs structured viva. Glob Res Anal. 2013;2:188-90.

27. Holloway PJ, Hardwick JL, Morris J, Start KB. The validity of assays and viva voce examining techniques. Br Dent J. 1967; 123: 227-32.

28. Khilnani AK, Charan J, Thaddanee R, Pathak RR, Makwana S, Khilnani G. Structured oral examination in pharmacology for undergraduate medical students: Factors influencing its implementation. Indian J Pharmacol [serial online]. 2015 [cited 2018 Apr 18]; 47: 546-50. Available from: http://www.ijp-online.com/text. asp?2015/47/5/546/165182.

29. Wass V, Wakeford R, Neighbour R, Van der Vleuten C. Achieving acceptable reliability in oral examinations: an analysis of the Royal College of General Practitioners membership examination's oral component. Medical Education. 2003; 37: 126-131.
30. Jefferies A, Simmons B, Ng E, Skidmore M. Assessment of multiple physician competencies in postgraduate training: utility of the structured oral examination. Adv in Health Sci Educ. 2011; 16: 569-577. DOI 10.1007/s10459-011-9275-6

31. Susan M, Brookhart SM, Jarol G, DeVoge. Testing a theory about the role of classroom assessment in student motivation and achievement. Appl Meas Educ. 1999; 12: 409-425.

32. Turan S, Valcke M, De Maeseneer J, Aper L, Koole S, De Wispelaere C, Deketelaere A, Derese A: A novel medical achievement selfefficacy scale (MASS): a valid and reliable tool. Med Teach. 2013; 35: 575-580.

33. Karaguven MHU. The adaptation of academic motivation scale to Turkish. Educ sci: Theory \& Practice. 2012; 12(4): 2611-18.

34. Dario CF, Cohen-Schotanus J, René AT. Assessment programs to enhance learning, Physical Therapy Reviews. 2017: P.1-4. DOI:10 $.1080 / 10833196.2017 .1341143$.

35. Cohen-Schotanus J. Student assessment and examination rules. Med Teach. 1999; 21(3): $318-321$.

36. Wigfield A, Eccles JS. Expectancy-value theory of achievement motivation. Contemporary Educational Psychology. 2000; 25(1): 68-81. DOI:10.1006/ceps.1999.1015 